\title{
Urban Climate Analysis with Remote Sensing and Climate Observations: A Case of Morogoro Municipality in Tanzania
}

\author{
Siwa Ernest ${ }^{*}$, Augustino R. Nduganda ${ }^{2}$, Japhet J. Kashaigili ${ }^{3}$ \\ ${ }^{1}$ Tanzania Forestry Research Institute, Morogoro, Tanzania \\ ${ }^{2}$ Tanzania Meteorological Agency, Dar Es Salaam, Tanzania \\ ${ }^{3}$ Sokoine University of Agriculture, Morogoro, Tanzania \\ Email: *siwa.ernest@taforitz.org
}

How to cite this paper: Ernest, S., Nduganda, A.R. and Kashaigili, J.J. (2017) Urban Climate Analysis with Remote Sensing and Climate Observations: A Case of Morogoro Municipality in Tanzania. Advances in Remote Sensing, 6, 120-131.

https://doi.org/10.4236/ars.2017.62009

Received: April 26, 2017

Accepted: June 12, 2017

Published: June 15, 2017

Copyright $\odot 2017$ by authors and Scientific Research Publishing Inc. This work is licensed under the Creative Commons Attribution International License (CC BY 4.0). http://creativecommons.org/licenses/by/4.0/

\section{Open Access}

\begin{abstract}
Rapid urbanization is threatening sustainable development of urban areas in Tanzania. Among the risks of rapid urbanization are Urban Heat Island (UHI) effect and climate change. While this has been noted, it is not known to what extent these risks are being realized in fast growing urban areas like Morogoro and other areas of similar geographic and climatic conditions. Therefore a study was conducted to assess the influence of urbanization on UHI and climate in Morogoro Municipality using remote sensing and climate data. Landsat imageries acquired in 1990, 2000 and 2015 were used to assess the change of impervious surface for the year 1990 to 2015 using a Classification and Regression Tree (CART). Radiant surface temperature and normalized difference vegetation index (NDVI) were derived from thermal band and reflectance bands respectively. Mann-Kendall test was used to analyze climate data for trends. Results revealed an increase of impervious surface (built up areas) from $9 \mathrm{~km}^{2}$ in 1990 to $48 \mathrm{~km}^{2}$ in 2000 and $82 \mathrm{~km}^{2}$ in 2015; which is associated with UHI. UHI was not apparent in 1990, but was apparent in 2000 and 2015 with the temperature rise of $1.08^{\circ} \mathrm{C}$ and $1.22^{\circ} \mathrm{C}$ respectively. A linear relationship between radiant surface temperature $\left(T_{B}\right)$ and percent Impervious Surface (ISA); and between $T_{B}$ and NDVI it revealed that NDVI is better indicator of variations in $T_{B}$ dynamics than percent ISA. Mann-Kendall test indicated a significant increasing trend in mean annual maximum temperature. The results imply that increasing ISA coupled with vegetation degradation has contributed to temperature rise and change. Consequently, Morogoro Municipality residents are likely to suffer heat stress due to rapid urbanization. It is recommended that education on the use of reflective surfaces should be given to the residents; and an effective master plan that protects vegetation should be in place.
\end{abstract}




\section{Keywords}

Radiant Temperature, Impervious Surfaces, Urban Heat Island, Random Forest Algorithm, Mann-Kendall Test

\section{Introduction}

Urbanization is the increase in the population of urban areas versus rural areas [1]. In Tanzania this is largely caused by rural to urban migration and re-classification on new urban areas [2]. This trend is increasing exponentially in Tanzania [3], having risen to $29.1 \%$ in 2012 compared with $5.7 \%$ in 1967 [3]. Similar to other Sub-Saharan countries, the challenge to urbanization in Tanzania is that it doesn't occur concurrently with the economic growth and development transformation that support it [4]. The consequence is the highest level of urban poverty in the world which is characterized by unequal access to decent housing, high proportion of urban poor living in slum, lack of basic urban services such as access to sanitation, clean water, energy, and solid waste disposal [5]. This poses risks of social instability, risks to infrastructure, health and climate change in urban areas of Tanzania [6].

Urbanization also exerts influence on microclimate by transforming the landscape from natural cover types to increasingly impervious urban land [1], and through human activities that produce emissions of heat, water vapor and pollutants. The outcome of this change can cause temperature in urban areas to be higher than in surrounding non-urbanized areas, an effect called Heat Island [1]. Heat island plus above mentioned risks of rapid urbanization threaten sustainable development of urban areas in Tanzania. In essence, sustainable development aims at promoting economic and social wellbeing, while protecting the environment [7].

To have a sustainable development of human settlements in Tanzania, the National Human Settlements Development Policy was formulated in 2000 [8]. However, current efforts in implementation of the policy are not sufficient to ensure sustainability of urban areas development. In Morogoro Municipality, $65 \%$ of population lives in unplanned and un-serviced settlements [9], and climate variability has caused an increase of waterborne diseases due to deterioration of water quality; and a decline of crop production [10] [11]. Shortage of water caused by rapidly growing population, coupled with increasing urban poverty, makes Morogoro Urban more at risk of not meeting sustainable development [9]. Moreover, as urbanization contributes to global warming, Urban Heat Island (UHI) will for sure influence the sustainable development [12].

To better illustrate the urbanization and its impacts on urban climate, remote sensing data have been widely used in urban heat islands investigation as well as for urban climatology research [1] [13]. In this study, remote sensing and geospatial techniques tools were used to study land surface processes and their interactions with the atmosphere in Morogoro Urban. The thermal characteristic of 
Morogoro Urban was identified from infrared radiative surface temperature. The surface temperature is of prime importance in understanding urban climatology as is a measure of the state of energy exchange at the surface, thus combines the influences of a number of processes that occur at the surface. The analysis also included the historical climate information to find the degree of association between the temperature variables.

It is envisaged that knowledge generated from this study will help in formulation of strategies for mitigation of global warming and Urban Heat Island effect for sustainable development of Morogoro Urban, and other developing cities in Tanzania as the urbanization characteristics are similar. Moreover, the study avails in filling a knowledge gap for Climate Change adaptation in Urban Areas of East Africa [14].

\section{Materials and Methods}

\subsection{Description of the Study Area}

Morogoro Urban District has an area of about 260 square kilometers, and is located between longitude $37^{\circ} 34^{\prime} 52^{\prime \prime} \mathrm{E}$ and $37^{\circ} 45^{\prime} 25^{\prime \prime} \mathrm{E}$ and between latitude $6^{\circ} 38^{\prime} 56^{\prime \prime} \mathrm{S}$ and $6^{\circ} 55^{\prime} 8^{\prime \prime} \mathrm{S}$ in Morogoro Region (Figure 1). Morogoro Region is

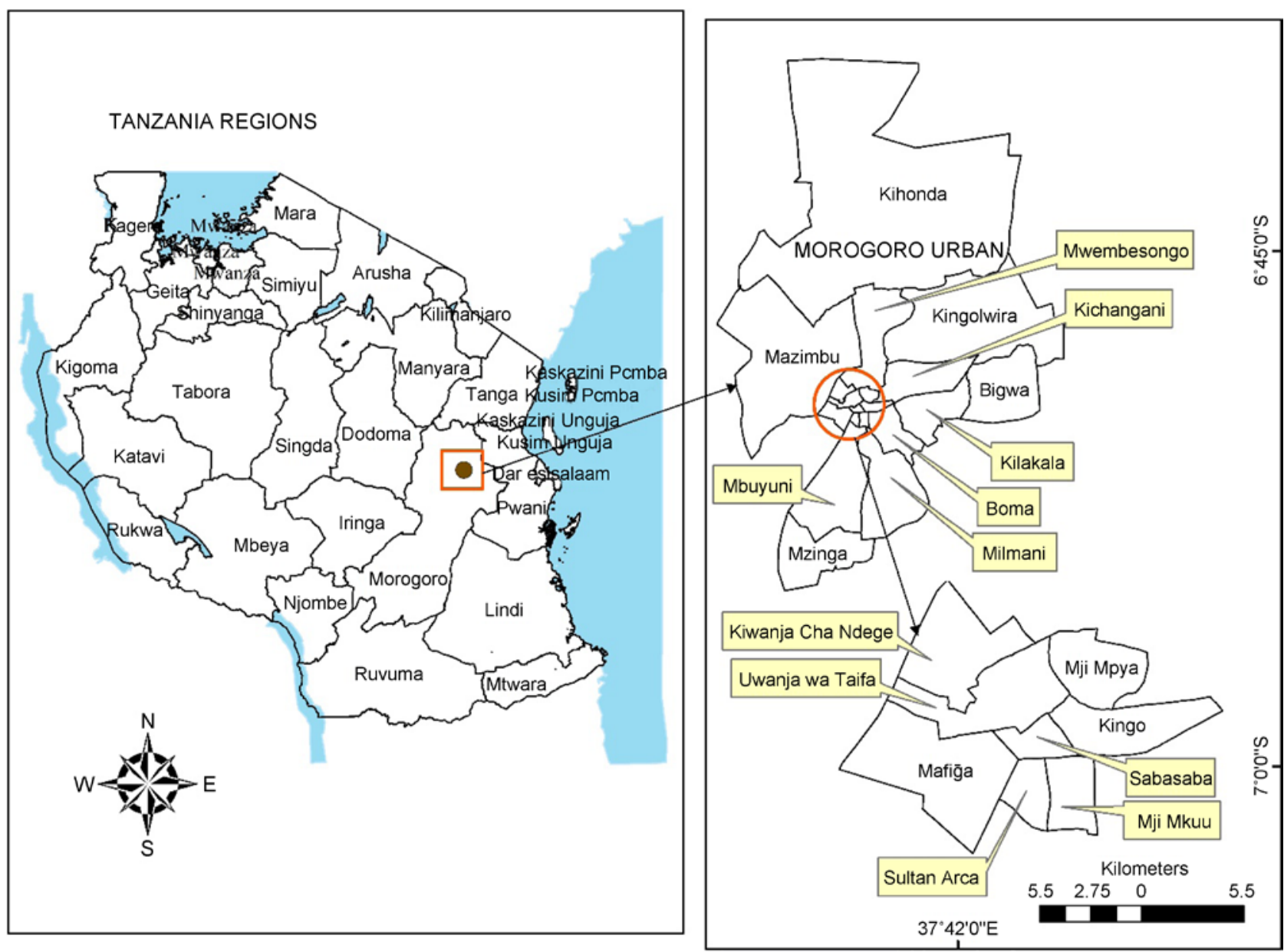

Figure 1. Morogoro municipality. 
among the regions with the highest level of urbanization in Tanzania [15], and Morogoro Municipality ranked fifth after Dar Es Salaam, Mwanza, Mbeya and Arusha City Councils [16]. The District has an average minimum and maximum temperature of $16^{\circ} \mathrm{C}$ and $33^{\circ} \mathrm{C}$ respectively. The average annual rainfall ranges between $821-1505 \mathrm{~mm}$ [17]. The current population size is about 315,866 [18] compared to 227,921 in 2002 [19] and 117,601 in 1988 [20]. The main economic activities include industries, subsistence and commercial farming, small scale enterprises and trade.

\subsection{Methods}

\section{Mapping Impervious Surfaces and Land Surface Temperature Estimation}

Landsat TM and ETM+ digital imagery with path/row 167/65 covering the study area were acquired and analyzed for three time periods, 1990, 2000 and 2015. The key image analysis procedures include image acquisition, mapping impervious surfaces, accuracy assessment and land surface temperature estimation.

\section{Landsat image acquisition}

Table 1 presents Landsat imagery used in the study. The imageries were obtained from Earth Explorer (earthexplorer.usgs.gov). To avoid the effects of seasonality, all images were acquired during the dry season. Moreover, the choice of the imageries was done in consideration of the cloud cover and images with minimum cloud cover were selected. The 2012 image was used to fill gaps in image 2015. These two images (2012 and 2015) had gaps, as they were captured when Scan Line Corrector (SLC) of Landsat ETM+ was off. The Mosaicking tool in ERDAS Imagine software was used to gap-fill the 2015 image. The 2012 image was chosen for gap filling as the gap phase statistic between the images was highest (100\%). Moreover, ground-truthing points were collected by a hand held GPS to guide mapping of impervious surfaces and for accuracy assessment.

Table 1. Landsat images used in the analysis of land cover changes.

\begin{tabular}{cccc}
\hline Image & Date of acquisition & Season & Cloud cover $(\%)$ \\
\hline Landsat TM & 24.10 .1990 & Dry & 12 \\
& 07.07 .2000 & Dry & 2 \\
Landsat ETM+ & 08.07 .2012 & Dry & 2 \\
& 17.07 .2015 & Dry & 3 \\
\hline
\end{tabular}

$\mathrm{TM}=$ Thermatic Mapper, ETM = Enhanced Thematic Mapper plus.

\section{Image pre-processing}

Landsat data were preprocessed from Digital Number to at-satellite reflectance (for six reflective bands) and at-satellite radiance temperature (thermal bands after being resampled to $30 \mathrm{~m}$ using the nearest neighbor algorithm) following approach described in [21] and in Landsat 7 User's handbook (Equations (1), (2) and (3)).

$$
L_{\lambda}=\frac{\left(L M A X_{\lambda}-\operatorname{LMIN}_{\lambda}\right)}{(Q C A L M A X-Q C A L M I N)} *(Q C A L-Q C A L M I N)+\operatorname{LMIN}_{\lambda}
$$


where: $L_{\lambda}=$ spectral radiance at the sensor's aperture

$Q C A L=$ quantized calibrated pixel value in $\mathrm{DN}$

$L M I N_{\lambda}=$ spectral radiance that is scaled to $Q C A L M I N$

$L M A X_{\lambda}=$ spectral radiance that is scaled to QCALMAX

$Q C A L M I N=$ minimum quantized calibrated pixel value (corresponding to $L M I N_{\lambda}$ in $\mathrm{DN}$

$Q C A L M A X=$ maximum quantized calibrated pixel value (corresponding to $L M A X_{\lambda}$ in DN

$$
\rho_{p}=\frac{\pi * L_{\lambda} * \mathrm{~d}^{2}}{E S U N * \cos \theta_{s}}
$$

where: $\rho_{p}=$ unitless planetary reflectance

$L_{\lambda}=$ spectral radiance

$\mathrm{d}=$ Earth-Sun distance

$E S U N_{\lambda}=$ mean solar exo-atmospheric irradiances

$\theta_{s}=$ solar zenith angle.

Radiance values from band 6 were converted to radiant surface temperature by the following equation

$$
T_{B}=\frac{K_{2}}{\ln \left(\frac{K_{1}}{L_{\lambda}}+1\right)}
$$

where: $K_{2}=$ calibration constant $2(1260.56$ and 1282.71 for TM and ETM+ respectively)

$K_{1}=$ calibration constant 1 (607.76 and 666.09 for TM and ETM+ respectively)

$L_{\lambda}=$ spectral radiance

$T_{B}=$ at-satellite brightness temperature.

Also, normalized difference vegetation index (NDVI) was derived from reflectance bands using the equation in [22]. NDVI is among most widely useful features for differentiation of vegetation and non-vegetation in urban areas [23]; and it has been used to study urban climate change associated with urbanization [24].

\section{Mapping impervious surfaces}

A Classification and Regression Tree (CART) was implemented using the random forest algorithm in R-software to classify the Landsat imagery into land use/land cover maps. The regression tree algorithm produces rule-based models for prediction of continuous variables based on training data. Random forest creates many decision trees based on input layers and then classifies a pixel using the decision trees based on training data [25]. Training data of impervious surfaces were created in QGIS by digitizing vector polygons in Landsat imagery guided by Google Earth (SPOT 5). Training data were restricted to the $2010 \mathrm{Na}$ tional Forest Resources Monitoring and Assessment (NAFORMA) land cover classes.

After classification, classes outside impervious surfaces were masked out by reclassifying the classes to $0 \%$ impervious. The impervious class (Built up) was 
reclassified to $100 \%$ impervious. Also, different percentage categories of impervious surfaces were determined based on Wards boundaries. Thereafter, postclassification method was used to estimate the change in impervious surface that have occurred between 1990 and 2000 and between 2000 and 2015 periods. Moreover, Zonal Statistics tool in QGIS evaluated mean temperatures in impervious and non-impervious classes for 1990, 2000 and 2015 years. Zonal Statistics tool summarize a raster layer within specified features. In this study, input raster layers were Radiant surface temperature layers, and specified features were impervious and non-impervious polygons for respective years.

Accuracy assessment

Accuracy of the Landsat-derived impervious surface estimates was assessed using field points and high spatial resolution SPOT 5 image by stratifying random sampling, wherein 246 reference points was used for validation. Error matrix (also called confusion matrix) was used to evaluate the accuracy (Table 2). The overall accuracy of classification reached $86.6 \%$ and the Kappa coefficient was 0.66 (66\%). This was accepted as the overall classification accuracy was above the recommended target of $85 \%$, with relatively even levels of accuracy for all classes [26].

Table 2. Error matrix.

\begin{tabular}{ccccc}
\hline Ground/Map & Impervious & Non Impervious & Totals & Producer's accuracy \\
\hline Impervious & 45 & 6 & 51 & $88 \%$ \\
Non Impervious & 27 & 168 & 195 & $86 \%$ \\
Totals & 72 & 174 & 246 & \\
User's accuracy & $62 \%$ & $95 \%$ & & \\
\hline
\end{tabular}

\section{Climate data analysis}

The study utilized historical climate data for the period from 1981 to 2012 (32 years) obtained from Tanzania Meteorological Agency (TMA), Morogoro Station to investigate Climate Change in Morogoro Municipality. Mean annual maximum temperature data was analyzed by Mann-Kendall test in order to determine monotonic trend over time as per equations described in [27]. Mann-Kendall test is a nonparametric statistical test widely used with environmental time series, as it is less sensitive to outliers and most robust for discovering trends in time series for which there may be missing observations [27] [28]. One advantage of using nonparametric test is that the data need not conform to any particular distribution [27]. R software was used to carry out the statistical Mann-Kendall test. In addition, linear trend line was plotted to compare results obtained from the Mann-Kendall test.

\section{Results and Discussion}

\section{Impervious surface and $T_{B}$ changes}

The land cover maps indicate an increase of impervious surface (built up areas) from 1990 to 2015. The impervious surface was $9 \mathrm{~km}^{2}$ in $1990,48 \mathrm{~km}^{2}$ in 2000 and $82 \mathrm{~km}^{2}$ in 2015 (Figure 2). By visually inspecting the maps, it was 
found that the expansion of impervious surface is more in Kihonda Ward. Mean Temperature $\left(T_{B}\right)$ for impervious, non-impervious and difference between $T_{B}$ in impervious and $T_{B}$ in non-impervious for three dates are presented in Table 3. In 1990, an Urban Heat Island (UHI) was not apparent, while, in 2000 and 2015 UHI was apparent wherein $1.22^{\circ} \mathrm{C}$ temperature difference in 2015 was the strongest UHI effect in Morogoro Urban. The spatial extent of UHI in 1990, 2000 and 2015 indicates that urban development is increasing the temperature of Morogoro Urban. The impervious surface emits and reflects more of solar radiations hitting the earth surface, which influences the urban temperatures and causing Urban Heat Island [29] [30].

UHI effect could be a reason for climate variability in Morogoro Urban, as [10] found that the climate is varying. The increasing UHI effect is likely to lead to discomfort of Morogoro Urban residents, as [31] stated that urban citizens are likely to suffer heat wave impacts more often due to UHI effect. The implications
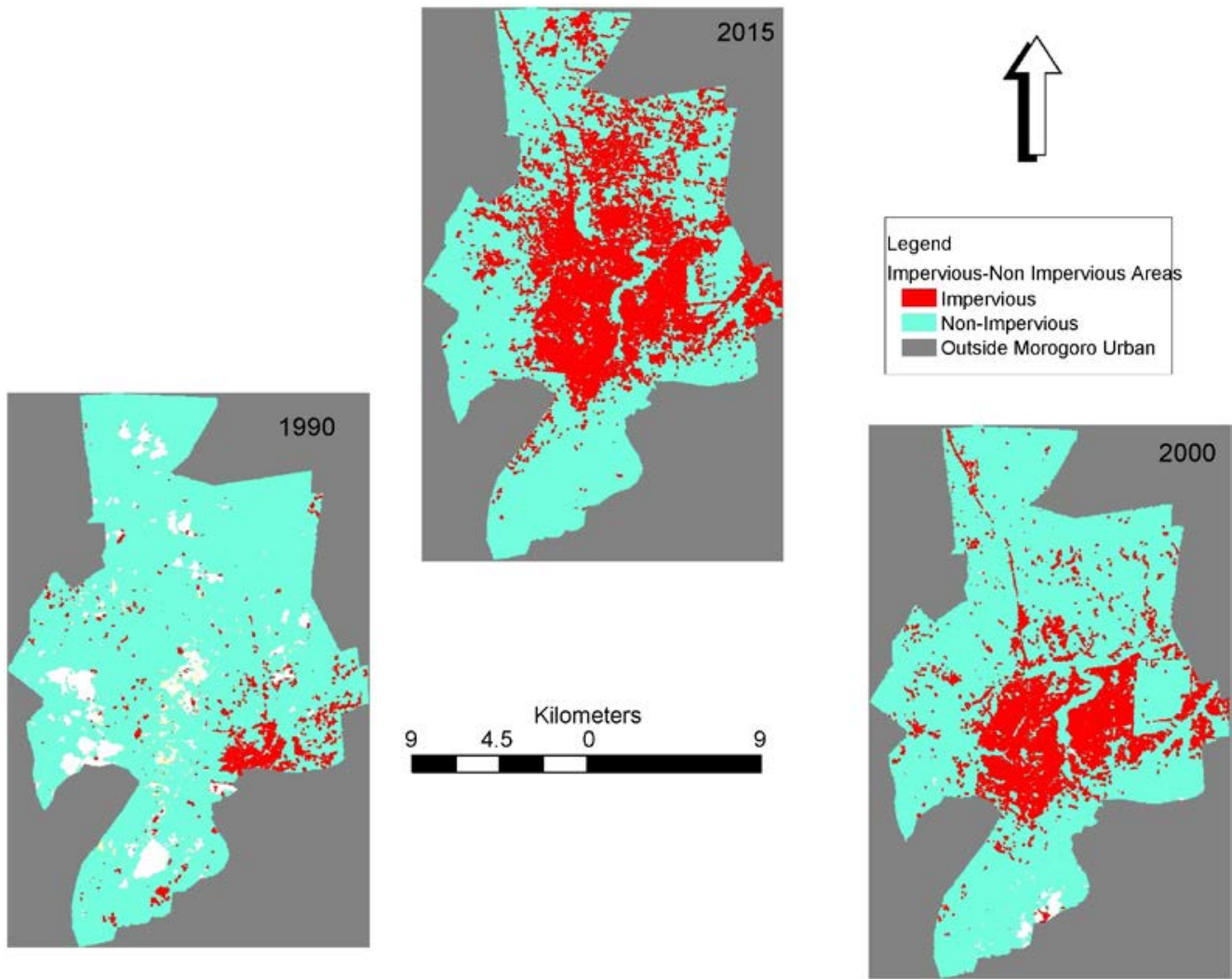

Figure 2. Impervious surfaces for year 1990, 2000 and 2015.

Table 3. Mean temperature of impervious and non-impervious surfaces and its difference.

\begin{tabular}{cccc}
\hline \multirow{2}{*}{ Years } & \multicolumn{2}{c}{ Mean Temperature $\left(T_{B}\right)$} & \multirow{2}{*}{$\Delta T$} \\
\cline { 2 - 3 } & Non-impervious & Impervious \\
\hline 1990 & 303.24 & 302.46 & -0.78 \\
2000 & 297.33 & 298.41 & 1.08 \\
2015 & 300.66 & 301.88 & 1.22 \\
\hline
\end{tabular}


of increasing UHI effect is that there is a need of having effective master plan as stated in the National Human Settlements Development Policy in order to mitigate UHI effect and ensuring sustainable development. Moreover, there is a need for educating Morogoro Urban residents on the use of light colored surfaces which reflect more sunlight and absorb less heat for adaptation of UHI effect. The use of reflective surfaces is among strategies used to mitigate UHI effect in sustainable cities [32] [33].

Radiant Surface Temperature $\left(T_{B}\right)$ relationships to percent impervious surface and NDVI

To further understand the impact of urbanization on $T_{B}$, the study investigated the links between $T_{B}$ and percent Impervious Surface Area (ISA), and between $T_{B}$ and NDVI for Morogoro Urban in 2015 using 100 randomly selected points. Figure 3 shows $T_{B}$ values associated with different percent ISA in Morogoro Urban. The linear regression of the points indicated a weak positive linear relationship between $T_{B}$ and percent ISA with a coefficient of determination value of $\mathrm{R}^{2}=0.06218(\mathrm{R}=0.25), \mathrm{F}$-statistic $=6.498$, and $\mathrm{p}$-value $=0.01235$. In contrast, the linear regression of the points between $T_{B}$ and NDVI indicated a moderate inverse linear relationship with a coefficient of determination value of

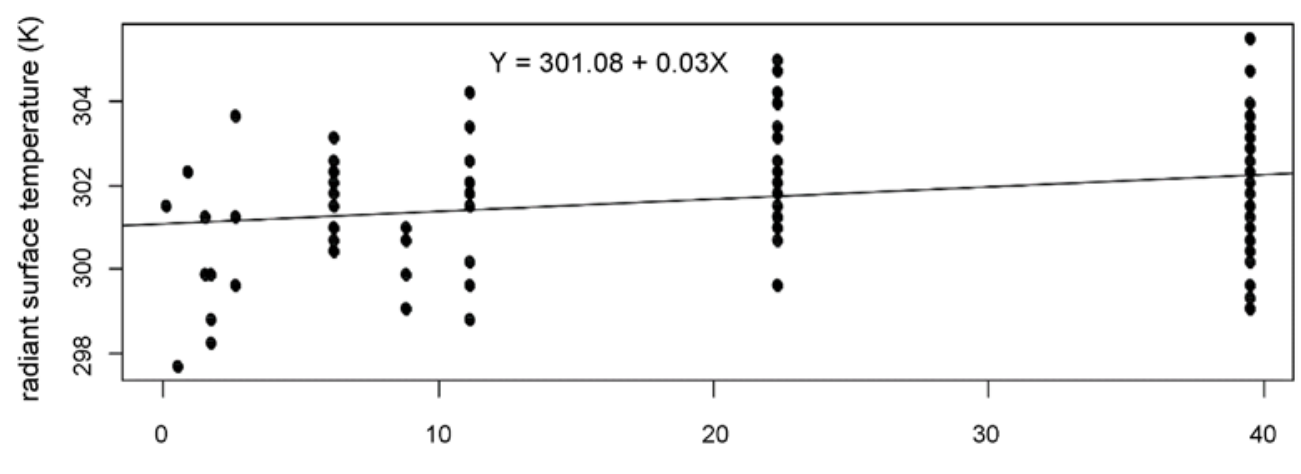

percent of impervious surfaces area

(a)

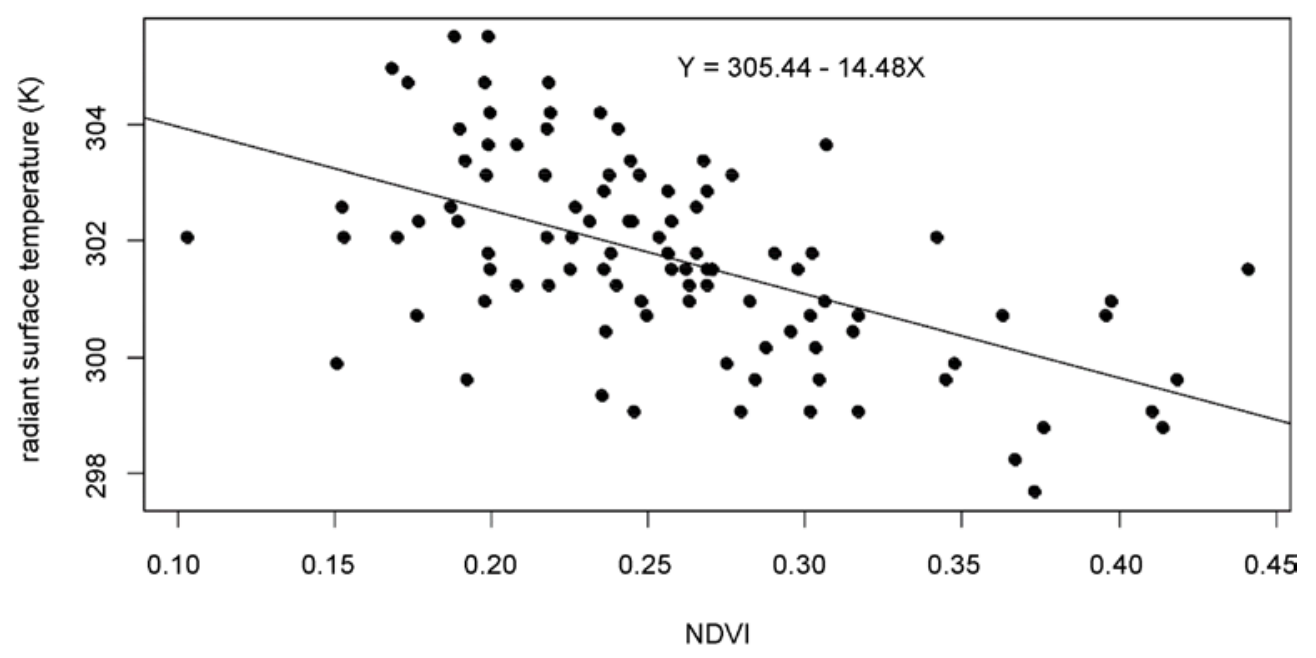

(b)

Figure 3. (a) \& (b) Relations between percentage impervious surface area, NDVI and $T_{B}$. 
$\mathrm{R}^{2}=0.3177(\mathrm{R}=-0.56), \mathrm{F}$-statistic $=45.64$, and $\mathrm{p}$-value $=1.02 \mathrm{e}-09 . \mathrm{P}$-value of these relationships proven results was statistically significant at the significance level of 0.05 . These linear relationships suggest that the variability of $T_{B}$ in Morogoro Urban is more explained by NDVI than percent ISA. This suggests NDVI to be a better indicator of variations in $T_{B}$ dynamics than percent ISA in Morogoro Urban. NDVI has been used traditionally in thermal remote sensing studies as the major indicator of urban climate, because vegetation absorbs sunlight energy which is used during photosynthesis [34].

\section{Climate data analysis}

Results of trend analysis using Mann-Kendall test (Table 4) indicate presence of statistically significant increasing trend in mean annual maximum temperature. This is also portrayed in (Figure 4) that shows a linear increasing trend in mean maximum temperature at a rate of $0.03^{\circ} \mathrm{C}$ per year equating to temperature rise associated with increase of $1 \%$ of 2015 impervious surface (Figure $3(\mathrm{a}))$. The increase of $0.03^{\circ} \mathrm{C}$ per year implies that mean maximum temperature has increased by $0.96^{\circ} \mathrm{C}$ during 1981-2012. A study by [7] also found that the trend of temperature in Morogoro Municipal to be increasing; wherein annual average temperature increased from $21.78^{\circ} \mathrm{C}$ in 2002 to $25.10^{\circ} \mathrm{C}$ in 2009 .

Overall, the study provides knowledge on the influence of urbanization (Built-up areas) on the urban climate. This knowledge is useful for UHI effect,

Table 4. Results of the Mann-Kendall test for max temperature data.

\begin{tabular}{cccc}
\hline Mann-Kendall Statistic(s) & Kendall's Tau & $\operatorname{Var}(\mathbf{S})$ & $\boldsymbol{p}$-value (two sided) \\
\hline 213 & 0.412 & 4137 & 0.00098 \\
\hline
\end{tabular}

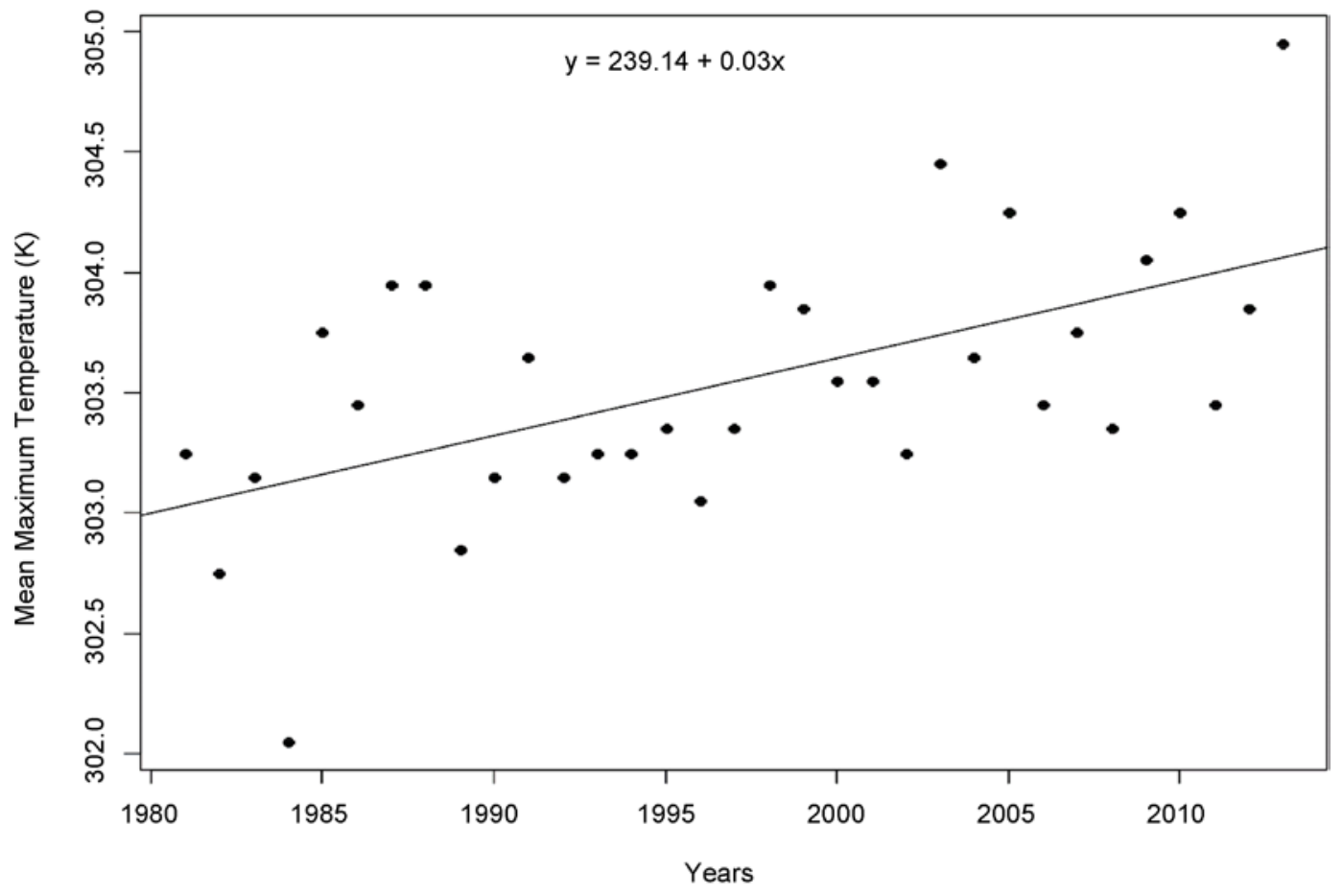

Figure 4. Mean maximum temperatures for Morogoro Urban. 
Climate change adaptation and mitigation in other developing cities of East Africa as well. Moreover, the study provides knowledge that will help in monitoring of urban climate in other urban areas in East Africa for generation of more knowledge, as the study covered only Morogoro Municipal.

\section{Conclusions}

The impervious surfaces have increased in Morogoro Urban from $9 \mathrm{~km}^{2}$ in 1990 to $82 \mathrm{~km}^{2}$ in 2015. The increase of impervious surface (built up area) has contributed to Urban Heat Island effect in Morogoro Urban. Also, different percent of impervious surface has effects on radiant surface temperature within the Morogoro Urban. Higher percent of impervious surface is correlated with higher mean radiant surface temperature.

The study also revealed that radiant surface temperature has negative correlation with NDVI within the area; and NDVI has greater influence to radiant surface temperature than impervious surfaces. Therefore, NDVI is better than percent impervious surfaces for UHI studies in Morogoro Urban.

The long term impact of increasing impervious surfaces coupled with vegetation degradation could modify climate condition in Morogoro Urban, as revealed by the increasing trend of mean annual maximum temperature of $0.03^{\circ} \mathrm{C}$ per year during 1981 to 2012. It is recommended that education on the use of light colored surface reflects more of solar radiation and absorbs less heat should be given to Morogoro Urban residents for adaptation to UHI effect; and effective master plan that protects natural environment and vegetation should be prepared in order to mitigate UHI effect and achieve sustainable urban development.

\section{References}

[1] Xian, G. and Crane, M. (2005) Evaluation of Urbanization Influences on Urban Climate with Remote Sensing and Climate Observations. http://www.isprs.org/proceedings/XXXVI/8-W27/xian.pdf

[2] Agwanda, A. and Amani, H. (2014) Population Growth, Structure and Momentum in Tanzania. THDR2014: Background paper No.7, ESRF Discussion Paper 61.

[3] Wenban-Smith, H. (2014) Population Growth, Internal Migration and Urbanization in Tanzania 1967-2012: A Census-Based Regional Analysis.

http://www.theigc.org/wp-content/uploads/2014/09/Wenban-Smith-2014-Working -Paper.pdf

[4] Bocquier, P., Otieno, A., Khasakhala, A. and Owuor, S. (2009) Urban Integration in Africa: A Socio-Demographic Survey of Nairobi. Dakar: CODESRIA.

[5] Arouri, M., Youssef, A.B., Nguyen-Viet, C. and Soucat, A. (2014) Effects of Urbanization on economic Growth and Human Capital Formation in Africa. PGDA Working Paper No.119.

https://cdn1.sph.harvard.edu/wp-content/uploads/sites/1288/2014/09/PGDA_WP_ 119.pdf

[6] World Economic Forum (WEF) (2015) Global Risks 2015. $10^{\text {th }}$ Edition. Insight Report. http://www3.weforum.org/docs/WEF_Global_Risks_2015_Report15.pdf

[7] Kates, R.W., Parris, T.M. and Leiserowitz, A.A. (2005) What Is Sustainable Devel- 
opment? Goals, Indicators, Values, and Practice. Environment: Science and Policy for Sustainable Development, 47, 8-21.

https://doi.org/10.1080/00139157.2005.10524444

[8] The United Republic of Tanzania (URT) (2000) National Human Settlements Development Policy. Government Printer, Dar Es Salaam.

[9] UN-HABITAT (2009) Tanzania: Morogoro Profile. Regional and Technical Cooperation Division, Nairobi.

[10] Steven, S. and Mkonda, M.Y. (2015) Climate Variability Impacts, Diseases and Human Health: The Case of Morogoro Municipalities, Tanzania. Archives of Business Research, 3, 78-90. https://doi.org/10.14738/abr.35.1535

[11] Mkonda, M.Y. (2015) Vulnerability of Climate Change and Adaptation Strategies on Agriculture: The Case of Morogoro Municipalities, Tanzania. Global Advanced Research Journal of Agricultural Science, 4, 725-734.

[12] Zoran, M., Savastru, R. and Savastru, D. (2015) Remote Sensing Image-Based Analysis for Effects of Urbanization on Climate Quantifying. 2013 6th International Conference on Developments in eSystems Engineering (DeSE), Abu Dhabi, 16-18 December 2013, 27-32. http://ieeexplore.ieee.org/document/7041087/

[13] Weng, Q. (2001) A Remote Sensing-GIS Evaluation of Urban Expansion and Its Impact on Surface Temperature in the Zhujiang Delta, China. International Journal of Remote Sensing, 22, 1999-2014.

[14] Mubaya, C.P., Jalloh, A. and Mogaka, H. (2014) Review of Research and Policies for Climate Change Adaptation in Urban Areas in East Africa. Working Paper 102.

[15] United Republic of Tanzania (2015) Migration and Urbanization Report. 2012 Population and Housing Census, Volume IV.

http://www.nbs.go.tz/nbs/takwimu/census2012/Migration_and_Urbanisation_Mon ograph.pdf

[16] Wenban-Smith, H. (2015) Population Growth, Internal Migration, and Urbanization in Tanzania, 1967-2012: Phase 2 (Final Report).

http://www.theigc.org/wp-content/uploads/2015/09/Wenban-Smith-2015-Working -paper.pdf

[17] United Republic of Tanzania (2016) Morogoro Region Investment Guide. President's Office, Regional Administration and Local Government, Morogoro, 87 p.

[18] National Bureau of Statistics (NBS) and Office of Chief Government Statistician (OCGS), Zanzibar (2013) 2012 Population and Housing Census: Population Distribution by Administrative Units; Key Findings. NBS and OCGS, Dar es Salaam, Tanzania.

[19] National Bureau of Statistics (NBS) (2012) 2002 Census Population Distribution as per 2012 Population Census Administrative Units.

http://www.nbs.go.tz/nbs/takwimu/census2012/Pop_dist_by_enu_me_area_as_per 2002_pop_and_housing_census.pdf

[20] United Republic of Tanzania (1997) Morogoro Region. Socio-Economic Profile. http://www.tzonline.org/pdf/Morogoro.pdf

[21] Finn, M.P., Reed, M.D. and Yamamoto, K.H. (2012) A Straight Forward Guide for Processing Radiance and Reflectance for EO-1, ALI, Landsat 5 TM, Landsat 7 ETM+, and ASTER.

http://cegis.usgs.gov/soil_moisture/pdf/A\%20Straight\%20Forward\%20guide\%20for \%20Processing\%20Radiance\%20and\%20Reflectance_V_24Jul12.pdf

[22] Linh, N.H.K. and van Chuong, H. (2015) Assessing the Impact of Urbanization on Urban Climate by Remote Sensing Perspective. A Case Study in Danang City, Viet- 
nam. The International Archives of the Photogrammetry, Remote Sensing and Spatial Information Sciences, Volume XL-7/W3.

[23] Zou, X ., Zhao, G., Li,J., Yang, Y. and Fang, Y. (2016) Object Based Image Analysis Combining High Spatial Resolution Imagery and Laser Point Clouds for Urban Land Cover. The International Archives of the Photogrammetry, Remote Sensing and Spatial Information Sciences, Volume XLI-B3.

[24] Voogt, J.A. and Oke, T.R. (2003) Thermal Remote Sensing of Urban Climates. Remote Sensing of Environment, 86, 370-384. https://doi.org/10.1016/S0034-4257(03)00079-8

[25] Breiman, L. (2001) Random Forests. Machine Learning, 45, 5-32. https://doi.org/10.1023/A:1010933404324

[26] Foody, G.M. (2002) Status of Land Cover Classification Accuracy Assessment. Remote Sensing of Environment, 80, 185-201. https://doi.org/10.1016/S0034-4257(01)00295-4

[27] Hipel, K.W. and McLeod, A.I. (2005) Time Series Modelling of Water Resources and Environmental Systems. Electronic Reprint of Our Book Originally Published in 1994. http://www.stats.uwo.ca/faculty/aim/1994Book/

[28] Addisu, S., Selassie, Y.G., Fissha, G. and Gedif, B. (2015) Time Series Trend Analysis of Temperature and Rainfall in Lake Tana Sub-Basin, Ethiopia. Environmental Systems Research, 4, 25. https://doi.org/10.1186/s40068-015-0051-0

[29] Ngie, A., Abutalab, K., Ahmed, F., Taiwo, O.J., Darwish, A.A. and Ahmed, M. (2015) An Estimation of Land Surface Temperature from Landsat ETM+ Images for Durban, South Africa. GeoTechRwanda 2015, Kigali, 18-20 November 2015. https://www.geotechrwanda2015.com/wp-content/uploads/2015/12/54a_Adeline-N gie.pdf

[30] Adeyemi, A., Botai, J., Ramoelo, A., Van der Merwe, F. and Tsela, P. (2015) Effect of Impervious Surface Area and Vegetation Changes on Mean Surface Temperature over Tshwane Metropolis, Gauteng Province, South Africa. South African Journal of Geomatics, 4.

[31] Kunz-Plapp, T., Hackenbruch, J. and Schipper, J.W. (2016) Factors of Subjective Heat Stress of Urban Citizens in Contexts of Everyday Life. Natural Hazards and Earth System Sciences, 16, 977-994. https://doi.org/10.5194/nhess-16-977-2016

[32] Rehan, R.M. (2016) Cool City as a Sustainable Example of Heat Island Management Case Study of the Coolest City in the World. HBRC Journal, 12, 191-204. https://doi.org/10.1016/j.hbrcj.2014.10.002

[33] Al-Obaidi, K.M., Ismail, M., Malek, A. and Rahman, A. (2014) Passive Cooling Techniques through Reflective and Radiative Roofs in Tropical Houses in Southeast Asia: A Literature Review. Frontiers of Architectural Research, 3, 283-297. https://doi.org/10.1016/j.foar.2014.06.002

[34] Yuan, F. and Bauer, M.E. (2007) Comparison of Impervious Surface Area and Normalized Difference Vegetation Index as Indicators of Surface Urban Heat Island Effects in Landsat Imagery. Remote Sensing of Environment, 106, 375-386. 
Submit or recommend next manuscript to SCIRP and we will provide best service for you:

Accepting pre-submission inquiries through Email, Facebook, LinkedIn, Twitter, etc. A wide selection of journals (inclusive of 9 subjects, more than 200 journals)

Providing 24-hour high-quality service

User-friendly online submission system

Fair and swift peer-review system

Efficient typesetting and proofreading procedure

Display of the result of downloads and visits, as well as the number of cited articles Maximum dissemination of your research work

Submit your manuscript at: http://papersubmission.scirp.org/

Or contact ars@scirp.org 